\title{
Seasonal Occurrence and Abundance of Mosquitoes in Pothwar Plateau
}

\author{
Arif Mehmood", Muhammad Naeem and Ata-ul-Mohsin \\ Department of Entomology, Pir Mehr Ali Shah, Arid Agriculture University Rawalpindi, \\ Pakistan
}

\begin{abstract}
A B S T RA C T
This research was carried out during 2014-16 in Pothwar Plateau. Collection of the mosquitoes was done from specified habitats fortnightly. A total of 3,997 adult and immatures of mosquitoes belonging to 5 genera and 28 species were collected. Culex spp. were found throughout year, Anopheles spp. through March-November. Armigeres spp. through January-November, Aedes spp. through April-November and Lutzia spp. were found in the months January-March and June-November. Seasonal distribution pattern is an asset in controlling any epidemic occurred due to mosquito vector. This pattern informs about the active period, favorable temperature and humidity ranges of the mosquitoes, hence the clues for controlling.
\end{abstract}

\section{INTRODUCTION}

$\mathrm{O}$ ur environment is being abruptly changed by the accumulation of greenhouse gases. Due to the accumulation of these gases, the temperature of earth is being continually raised causing floods, melting of glaciers, unexceptional rains, long dry spells, etc. The survival and developmental cycles of insects both depend highly on the fluctuations in temperature (Afrane et al., 2012).

Mosquitoes (Diptera: Culicidae) have well adapted to the environment. Temperature affects the life cycle of mosquitoes. The life cycle is lengthened, when the temperature increases up to a limit, after that mosquitoes die. Temperature of water bodies also affects the larval distribution of mosquitoes in the water bodies (Rattanarithikul et al., 2005). The Life cycle is shortened, when temperature decreases up to a limit, after that mosquito hibernates. Humidity also affects the life cycle of mosquitoes. At the optimum level, mosquitoes survive the best and breeds highly.

Mosquitoes hibernate in winter season in the adult stage in different habitats, including tree holes, drains, burrows, caves, mines, man-made woods, etc. when the temperature goes down beyond the limits or these also can pass the winter season in larval stage. Diapause in winter is also observed in mosquitoes in the egg stage. The quiescent eggs only hatch after the rain or flood. Adults can oviposit

\footnotetext{
Corresponding author: amsentomologist@gmail.com 0030-9923/2022/0003-1163 \$ 9.00/0

Copyright 2022 Zoological Society of Pakistan
}

in dry and cold seasons (Almiron and Brewer, 1994).

Most of the mosquitoes have highest population index in spring season or after the heavy monsoon (Reisen, 1978). The development of mosquitoes slows down in the cool season of the areas having warmer climates (Almiron and Brewer, 1994).

Mosquitoes are vectors of many life-threatening diseases. Vector control requires detailed information about the ecology of the vector, hence this study was conducted.

\section{MATERIALS AND METHODS}

From the four districts of Pothwar, including Rawalpindi, Attock, Jhelum and Chakwal sampling was done from specified sampling points, including animal sheds, graveyard, scrap yard, park, forest area, crop area, residential area, forest area and stream fortnightly during 2014-2016 to get the seasonal distribution pattern of each genus and species. The immature stages and adults of mosquitoes were collected with the help of dipper, aerial net and dry $\mathrm{CO}_{2}$ trap (Mehmood et al., 2016). A White sheet and animal capture method was also used. Light traps having UV bulbs were also used. The adults collected were killed using killing jar, preserved in wooden boxes and labeled with habitat, date, location information. Immature stages were reared for emergence of adults. Identification was done under the microscope CZM6 and SWIFT. The quantitative data was analysed using SPSS 16.0 (Zahirnia and Hamid, 2014) and Microcal Origion 6.0 (Edwards, 2002). In SPSS, standard error and percentages 
were calculated, while graphs were made using Microcal Origion.

\section{RESULTS AND DISCUSSION}

The distribution pattern of Anophlese spp. during different months of the year was uneven (Fig. 1). The presence of Anopheles spp. was observed during March and November. An increasing trend in population was seen from March to May, which decreases during June and increases during July and August, then a gradual decrease in population was seen from September to November.



$\mathbf{A}$

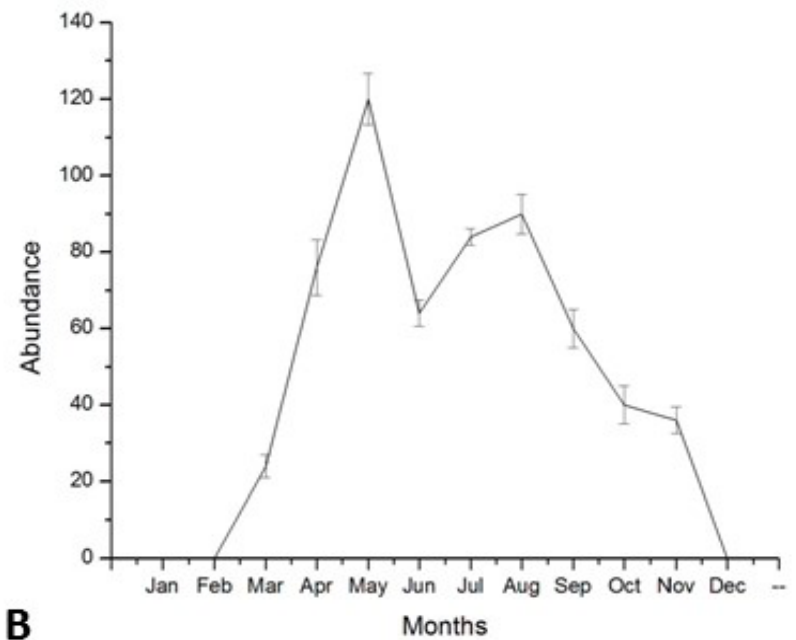

Fig. 1. Seasonal distribution of Anopheles spp. during 2014-15 (A) and 2015-16 (B).

Species composition and seasonal distribution of Anopheles spp. showed different trend throughout year
(Table I). Anopheles annularis was present during AprilAugust. The highest percentage (34.37\%) was found during the month of May followed by April (28.12\%) and July $(25 \%)$, while the least percentage $(6.25 \%)$ was found during the month of June and August. Anopheles culicifacies was present during the months May-September and November. The highest percentage (38.88\%) was found in July, while the least (5.55\%) was present during the May and June. Anopheles fluviatilis was present during July-September. This was found in high abundance (50\%) during the month of August, while in low abundance $(25 \%)$ during July and September. Anopheles maculates was found during April-August. The highest abundance $(36.36 \%)$ was present during the month of May followed by $(18.18 \%)$ during the months April, June and July, while the least abundance $(9.09 \%)$ during the month of August.
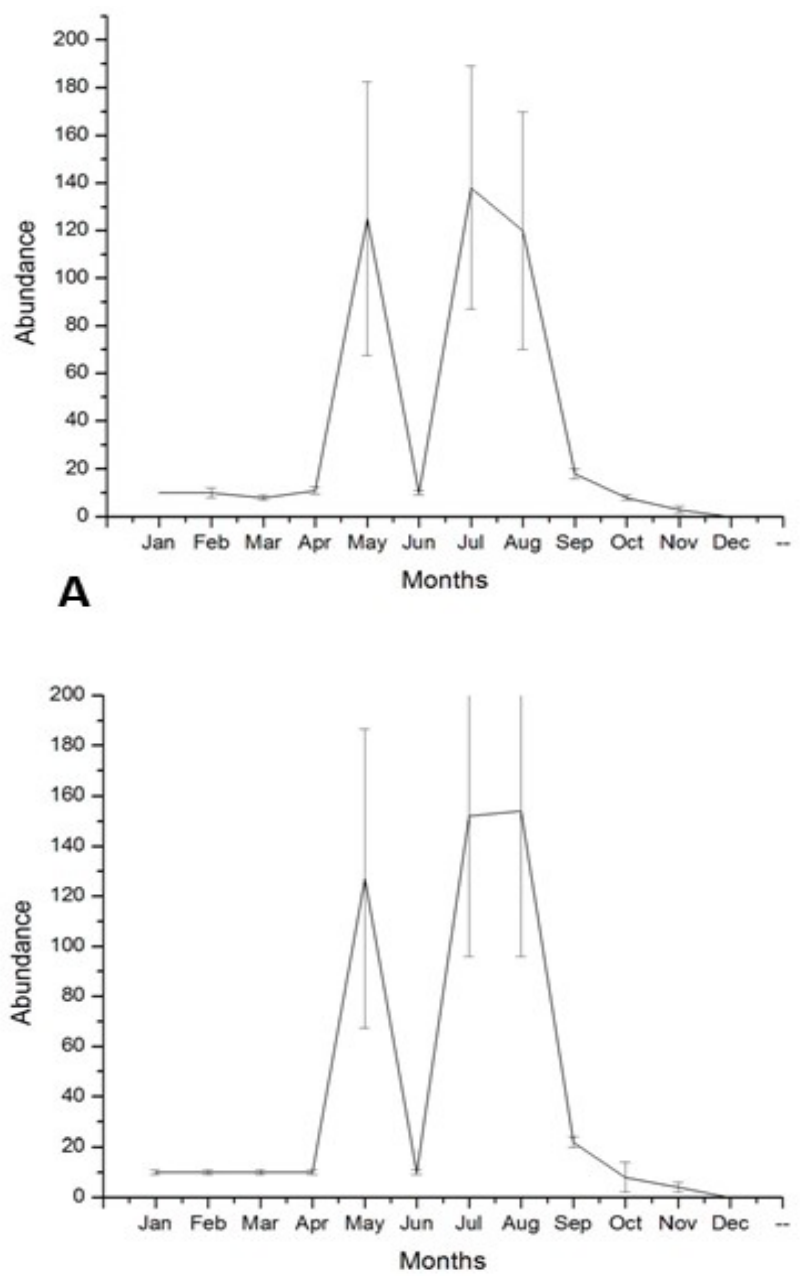

B

Fig. 2. Seasonal distribution of Armigeres spp. during 2014-15 (A) and 2015-16 (B). 
Armigeres spp. were distributed unevenly throughout year (Fig. 2). The presence of Armigeres spp. was found throughout year except during the month of December. The population was very low during the months JanuaryApril, June, September and November. An increasing trend in the population during the months May, July and August is seen.

The highest abundance $(27.02 \%)$ was present during the month of July followed by $(25.67 \%)$, while the least abundance (2.70\%) was found during the month of October. Armigeres obturbans was present during January-October. The highest abundance (30.47\%) was present during August followed by (29.79\%) during the month of July, while the least abundance (1.35\%) was present during JanApril and October (Table I).
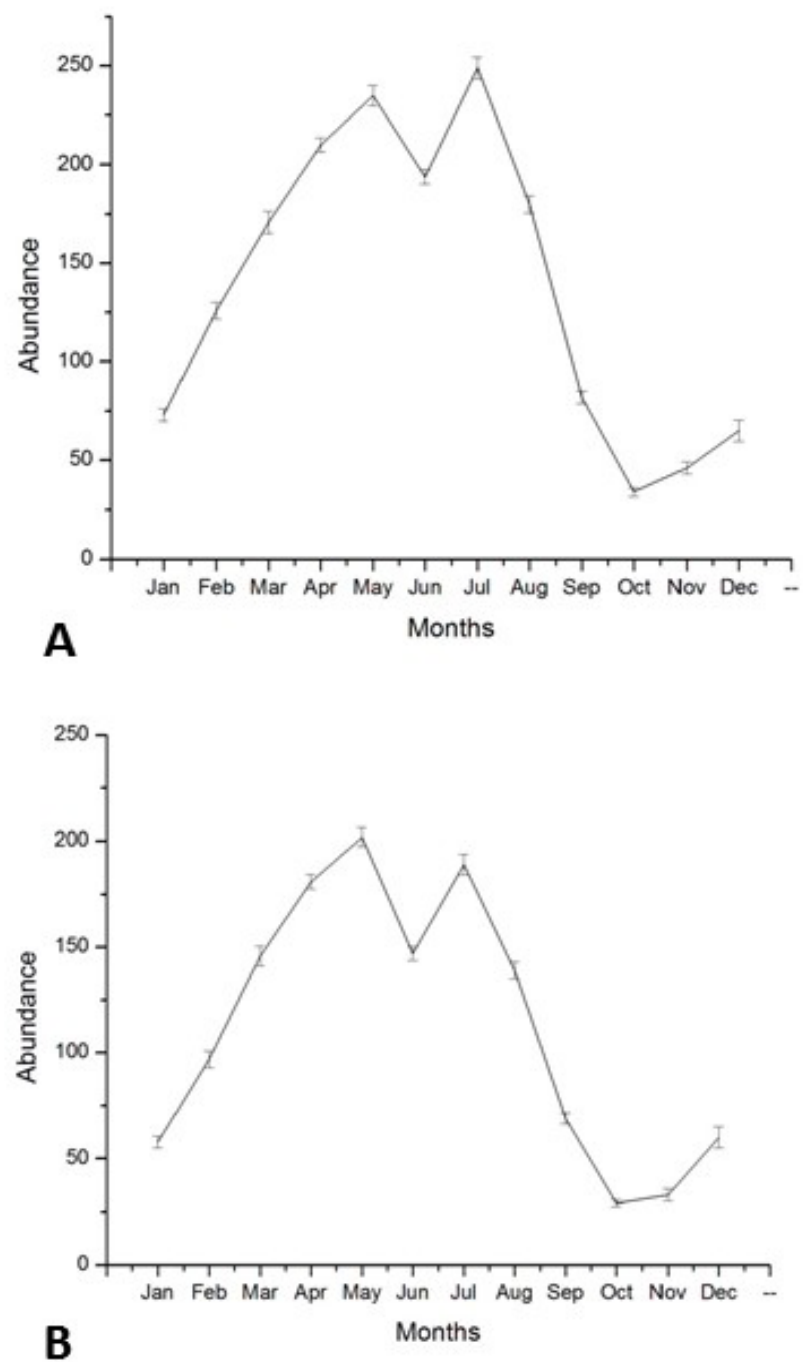

Fig. 3. Seasonal distribution of Culex spp. during 2014-15 (A) and 2015-16 (B).
Figure 3 represents that Culex spp. were found throughout year in a healthy and good population. An increasing trend in population was observed from JanuaryApril, then a decrease during June; again increase in population during July. The population decrease during August, September and October, then a little increase in population during November and December is observed.

An uneven trend in species composition and abundance of Culex spp. was seen throughout year (Table I). Culex cornotus was present during March-August. The highest abundance $(32.43 \%)$ was found during the month of July, while the least $(2.70 \%)$ was found during the month of March. Culex edwardsi was present during the months March-August. In the month of March abundance was the highest $(37.5 \%)$, while it was low $(12.5 \%)$ in all the remaining months. Culex fatigans was present during the months April-September. The highest abundance $(18.36 \%)$ was found during the month April, while it was low (16.32\%) during all the remaining months. Culex fuscitarsis was present during January-March. Abundance was high (28.57\%) during the months January, February and April, while low (14.28\%) during March. Culex malayi was present during the months January-April and June. It was present in the highest abundance (31.57\%) during the month of March, while the lowest abundance $(10.52 \%)$ was found during the month of June.

Culex nilgiricus was present during FebruarySeptember. The highest abundance (18.51\%) was present during the month of July, while the least abundance (7.40\%) was found during the month of June. Culex pluvialis was present during the months January-August. The highest abundance $(53.19 \%)$ was found during the month of April followed by (34.04\%) during May. Low abundance $(2.12 \%)$ was found during the remaining months. Culex seniori was present during the months January-August. The highest abundance $(25.92 \%)$ was found during the month of June, while the least abundance (3.70\%) was found during February, March and April. Culex tenuipalpis was present during January, March-August. The highest abundance $(55.88 \%)$ was found during the month of April followed by $(29.41 \%)$, while low abundance $(2.94 \%)$ was found during the remaining months. Culex theileri was found during March-August. The highest abundance $(42.30 \%)$ was found during the month of March, while the least abundance $(5.79 \%)$ was found during June, July and August. Culex vagans was present throughout year with the highest abundance (15.89\%) during February, while the least abundance (2.93\%) during March. Culex vishnui was present during the months January, March-July and September, October. The highest abundance (20.79\%) was found the month of June and July, while the least abundance $(1.98 \%)$ was found during the month of January. 
Table I. Seasonal distribution of Anopheles spp., Armigeres spp., Culex spp., Aedes spp. and Lutzia spp. during 201416 (Percentages).

\begin{tabular}{|c|c|c|c|c|c|c|c|c|c|c|c|c|}
\hline Mosquito species & Jan & Feb & Mar & Apr & May & Jun & July & Aug & Sep & Oct & Nov & Dec \\
\hline Anopheles annularis & 0 & 0 & 0 & 28.12 & 34.37 & 6.25 & 25 & 6.25 & 0 & 0 & 0 & 0 \\
\hline Anopheles culicifacies & 0 & 0 & 0 & 0 & 5.55 & 5.55 & 38.88 & 16.66 & 16.66 & 0 & 16.66 & 0 \\
\hline Anopheles fluviatilis & 0 & 0 & 0 & 0 & 0 & 0 & 25 & 50 & 25 & 0 & 0 & 0 \\
\hline Anopheles maculates & 0 & 0 & 0 & 18.18 & 36.36 & 18.18 & 18.18 & 9.09 & 0 & 0 & 0 & 0 \\
\hline Anopheles splendidus & 0 & 0 & 0 & 4.54 & 54.54 & 13.63 & 18.18 & 4.54 & 4.54 & 0 & 0 & 0 \\
\hline Anopheles stephensi & 0 & 0 & 7.45 & 17.67 & 14.36 & 7.45 & 7.45 & 14.08 & 12.43 & 11.60 & 7.45 & 0 \\
\hline Anopheles tessellates & 0 & 0 & 0 & 0 & 20.45 & 40.90 & 20.45 & 18.18 & 0 & 0 & 0 & 0 \\
\hline Anopheles theobaldi & 0 & 0 & 0 & 0 & 0 & 0 & 40 & 60 & 0 & 0 & 0 & 0 \\
\hline Armigeres kuchingensis & 5.40 & 5.40 & 5.40 & 5.40 & 5.40 & 5.40 & 27.02 & 25.67 & 6.75 & 2.70 & 5.40 & 0 \\
\hline Armigeres obturbans & 1.35 & 1.35 & 1.35 & 1.35 & 27.76 & 1.35 & 29.79 & 30.47 & 3.83 & 1.35 & 0 & 0 \\
\hline Culex cornotus & 0 & 0 & 2.70 & 13.51 & 13.51 & 18.91 & 32.43 & 18.91 & 0 & 0 & 0 & 0 \\
\hline Culex edwardsi & 0 & 0 & 37.5 & 12.5 & 12.5 & 12.5 & 12.5 & 12.5 & 0 & 0 & 0 & 0 \\
\hline Culex fatigans & 0 & 0 & 0 & 18.36 & 16.32 & 16.32 & 16.32 & 16.32 & 16.32 & 0 & 0 & 0 \\
\hline Culex fuscitarsis & 28.57 & 28.57 & 14.28 & 28.57 & 0 & 0 & 0 & 0 & 0 & 0 & 0 & 0 \\
\hline Culex malayi & 21.05 & 21.05 & 31.57 & 15.78 & 0 & 10.52 & 0 & 0 & 0 & 0 & 0 & 0 \\
\hline Culex nilgiricus & 0 & 11.11 & 11.11 & 14.81 & 15.74 & 7.40 & 18.51 & 13.88 & 7.40 & 0 & 0 & 0 \\
\hline Culex pluvialis & 2.12 & 2.12 & 2.12 & 53.19 & 34.04 & 2.12 & 2.12 & 2.12 & 0 & 0 & 0 & 0 \\
\hline Culex seniori & 4.93 & 3.70 & 3.70 & 3.70 & 22.22 & 25.92 & 24.69 & 11.11 & 0 & 0 & 0 & 0 \\
\hline Culex tenuipalpis & 2.94 & 0 & 2.94 & 55.88 & 29.41 & 2.94 & 2.94 & 2.94 & 0 & 0 & 0 & 0 \\
\hline Culex theileri & 0 & 0 & 42.30 & 9.61 & 30.76 & 5.76 & 5.76 & 5.76 & 0 & 0 & 0 & 0 \\
\hline Culex vagans & 9.53 & 10.26 & 2.93 & 5.86 & 8.80 & 9.77 & 8.55 & 7.82 & 5.86 & 5.86 & 8.80 & 15.89 \\
\hline Culex vishnui & 1.98 & 0 & 14.85 & 14.85 & 14.85 & 20.79 & 20.79 & 0 & 5.94 & 5.94 & 0 & 0 \\
\hline Aedes aegypti & 0 & 0 & 0 & 0 & 0.99 & 0.99 & 21.18 & 25.94 & 11.08 & 19.60 & 20.19 & 0 \\
\hline Aedes albopictus & 0 & 0 & 0 & 1.36 & 22.61 & 21.79 & 22.61 & 22.61 & 5.72 & 3.26 & 0 & 0 \\
\hline Lutzia raptor & 0 & 0 & 0 & 0 & 0 & 0 & 25 & 0 & 25 & 25 & 25 & 0 \\
\hline Lutzia vorax & 4.34 & 17.39 & 4.34 & 0 & 0 & 17.39 & 26.08 & 26.08 & 0 & 0 & 4.34 & 0 \\
\hline
\end{tabular}

The occurrence and abundance trends of Aedes genus throughout year was uneven as is shown in Figure 4. This genus was present during April-November. Species composition and seasonal abundance of Aedes spp. were in an uneven trend during the year (Table I). Aedes aegypti was present during May-November. The highest abundance (25.94\%) was found during August, while the least abundance $(0.99 \%)$ was found during May and June. Aedes albopictus was present during the months AprilOctober. The highest abundance (22.61\%) was found during the months May, July and August, while the least abundance $(3.26 \%)$ was found during October.

The occurrence and seasonal abundance of Lutzia spp. throughout year showed an uneven trend (Fig. 5). Lutzia spp. were present during January-March and JuneNovember. The population was low during January, March,
September and October. An increasing trend in population is seen during February, June and July then population decreases during August and November.

Table I shows the species composition and seasonal abundance of Lutzia spp. Lutzia raptor was found during July, September-November. The presence was found in equal abundance. Lutzia vorax was present during January-March, June-August and November. The highest abundance $(26.08 \%)$ during July and August, while the least abundance (4.34\%) during the months January, March and November.

Mosquitoes adapt different practices as a response to the changes in temperature like higher temperature (within limits) produces rapid development in larvae, short time interval between blood meals and short life span for adults. We collected Aedes aegypti during the months May- 
November when the rainy season starts and till late rainy season. Rajput and Singh (1990), Rajput and Kulkarni (199o) and Leisnham et al. (2014) found this mosquito in the same months from the same type of environment. In March, April and December the temperature was greater and humidity was less than Pothwar.


Fig. 4. Seasonal distribution of Aedes spp. during 2014-15 (A) and 2015-16 (B).

Armigeres obturbans is found throughout year in Pothwar Region. The population was present in the months November and December, but was low because of the very low temperature and high humidity. Our results are in accordance with Rajput and Singh (1990), Rajput and Kulkarni (1990), Naz and Maryam (2014).

In Pothwar region Culex theileri is found in the months March to August as did Ali et al. (2013), Kioulos et al. (2014), while some scientists Kheir et al. (2010) and Banafshi et al. (2013) found this mosquito during the months September and October. Culex vishnui was collected in the months Jan, March-July and September. In Feb. when the temperature was low and there was fog unexpectedly, Culex vishnui was not found. In August there was high rainfall, which suppressed its population. Our results are in conformity with Ali et al. (2013) and Ali and Rasheed (2009) with a little exception that they collected this mosquito in the months of June, August and September also and found no population January. This was due to unexpected changes in temperature and humidity in our area.
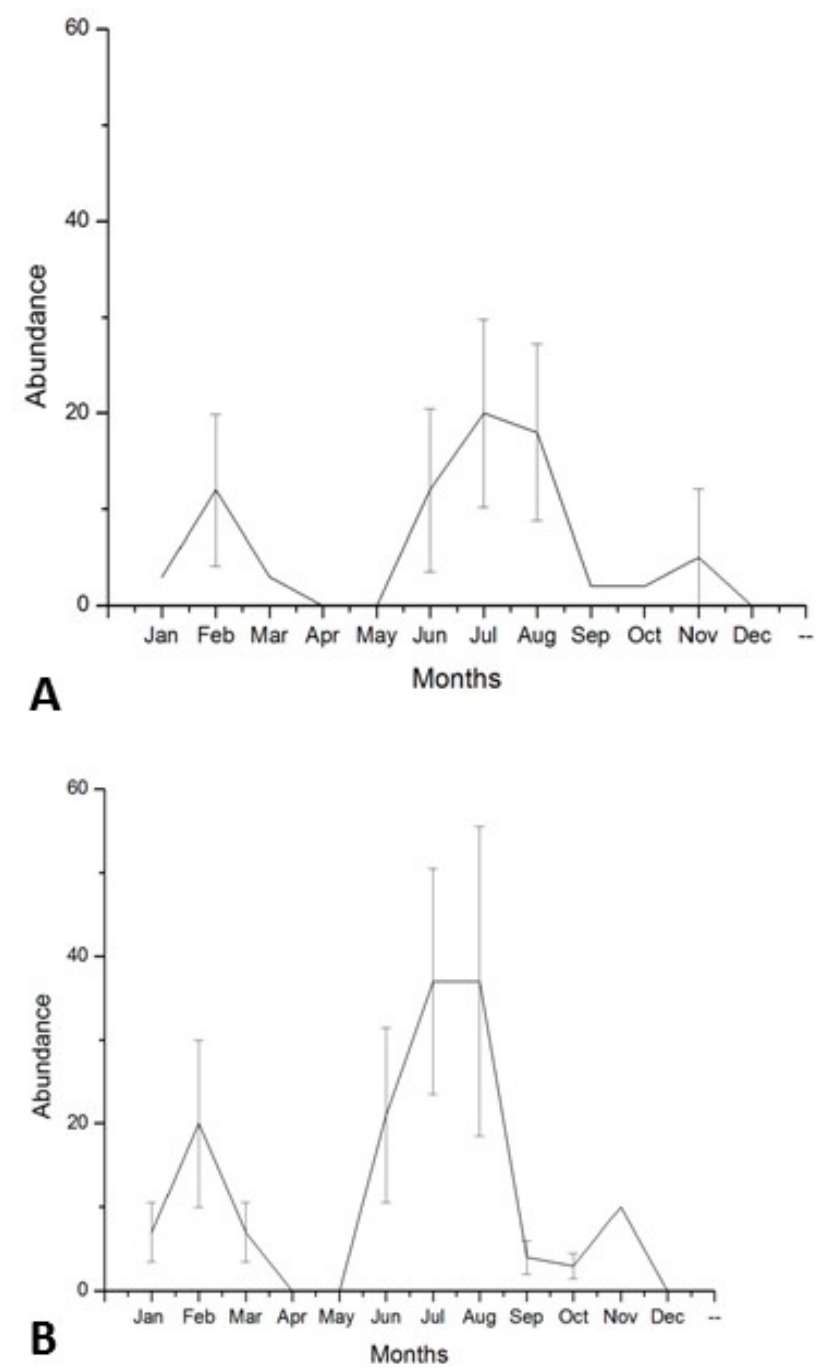

Fig. 5. Seasonal distribution of Lutzia spp. during 2014-15 (A) and 2015-16 (B).

Aedes albopictus was recorded during the months May-November as was recorded by Rajput and Singh (1990), Leisnham et al. (2014), while Naz and Maryam 
(2014) and Rajput and Kulkarni (1990) found this mosquito in March, April and Unexpectedly, Culex vegans has unique survival range and found throughout the year it has adapted well in our region. Rajput and Kulkarni (1990) collected this mosquito only in March-July and September.

We collected Anopheles stephensi in the months March-November, our results are in conformity with Ali and Rasheed (2009), Kheir et al. (2010), Ali et al. (2013) and Ilahi and Salman (2013) but different from AzariHamidian (2011) as there was severe and unexpected fog in our region in Feb. Anopheles fluviatilis was recorded in the months May-September. It is because it does not tolerate low temperature. Our results are in conformity with Ali et al. (2013) and Ilahi and Salman (2013), but not in concordance with the findings by Ali and Rasheed (2009) and Dhimal et al. (2014) as they collected this mosquito in the month of October, when it is cold in this area, which does not support its survival.

Anopheles maculatus was collected in the months May-August, when the temperature is usually high in this region. The results are supported by different previous studies, including Dhimal et al. (2014), but the results by Ali et al. (2013) and Ilahi and Salman (2013) collected this mosquito in April and September, when the summer starts and after the summer season when temperature is not that high which is preferred by this mosquito. We recorded Anopheles culicillahi and Salman (2013) have the same findings, but Ali et al. (2013), Ali and Rasheed (2009) collected in October and April when the temperature is usually low in the Pothwar region compared with others, so we have not recorded this species in these months.

Anopheles tesselatus was recorded during the months May-August, which clearly shows its nature to like hot environment. Anopheles annularis is found during the months April-August, from the start of summer till the end. Other than Anopheles Stephens, most of the Anopheles mosquitoes usually prefer the hot and rainy season. Our results are in accordance with Ilahi and Salman (2013) and Dhimal et al. (2014).

We recorded Anopheles splendidus during the months April-September, which is a little different behavior than others as it survives during the month of September, when it is cold. Our results are in partial conformity with Ilahi and Salman (2013). We collected Culex pluvialis during the months January-August but not in the months when temperature is very low. Our results are not in accordance with Tyagi et al. (2015), who collected this mosquito in the winter months.

Culex malayi was collected in the months JanuaryApril and July, when the temperature was not much high, Tyagi et al. (2015) have the same findings as ours. Culex fuscitarsis was collected in the months January-April, in the spring season, mostly our results not in accordance with Qasim et al. (2014). According to our findings and Tyagi et al. (2015), Lutzia vorax likes more humidity.

Lutzia raptor is mostly collected in post moonson season; our results are in accordance with Qasim et al. (2014). We collected Culex cornotus during spring and summer season, but Tyagi et al. (2015) collected this in the month of January. Culex fatigans was collected in the months April-October, which shows that this mosquito spp. like high temperature, our results are in partial accordance with Qasim et al. (2014).

We collected Culex nilgiricus in early summerearly winter, our findings do not match with Tyagi et al. (2015), who collected this species in the winter season. Culex edwardsi was collected in spring and summer season, which match with the findings of Tyagi et al. (2015). Armigeres kuchingensis was collected throughout year except the month of December, which is in partial conformity with Tyagi et al. (2015).

This study gave us detailed and updated information about the seasonal distribution of mosquitoes, using this information we can control and predict any epidemic in this region and hence can save many precious lives.

\section{CONCLUSION}

In the present study, Anopheles spp. were found through March-November. The highest population was observed during May, while the lowest was observed during March. Armigeres spp. were found through January-November, the highest population was observed during August, while the lowest population was observed during November. Culex spp. were found throughout year, the highest population was observed during July, while the lowest population was observed during October. Aedes spp. were found from April to November, the highest population was observed during August, while the low population was observed during April. Lutzia spp. was found in the months January-March and June-November, the highest population was observed during July, while the lowest population was observed during September and October.

\section{ACKNOWLEDGMENT}

We are highly thankful to the Pakistan Science Foundation, Islamabad and Department of Entomology, Pir Mehr Ali Shah, Arid Agriculture University Rawalpindi.

\section{Statement of conflict of interest}

The authors have declared no conflict of interest. 


\section{REFERENCES}

Afrane, Y.A., Githeko, A.K. and Yan, G., 2012. The ecology of mosquitoes in an irrigated vegetable farm in Kumasi, Ghana: abundance, productivity and survivorship. Par. Vec., 5: 233. https://doi. org/10.1186/1756-3305-5-233

Ali, N. and Rasheed, S.B., 2009. Determination of species composition of mosquitoes found in Palosai stream, Peshawar. Pak. Entomol., 31: 47-51.

Ali, N., Marjan, Khan, K. and Kausar, A., 2013. Study on mosquitoes of Swat Ranizai sub division of Malakand. Pakistan J. Zool., 45: 503-510.

Almiron, W.R. and Brewer, M.E., 1994. Immature stages of mosquitoes (Diptera: Culicidae) collected during the autumn-winter period in Cordoba Province, Argentina. Mem. I Oswaldo Cruz, 89: 625-628. https://doi.org/10.1590/S007402761994000400020

Azari-Hamidian, S., 2007. Checklist of Iranian mosquitoes (Diptera: Culicidae). J. Vec. Ecol., 32: 235-242. https://doi.org/10.3376/10811710(2007)32[235:COIMDC]2.0.CO;2

Banafshi, O., Abai, M., Ladonni, H., Bakhshi, H., Karami, H. and Azari-Hamidian, S., 2013. The fauna and ecology of mosquito larvae (Diptera: Culicidae) in Western Iran. Turk. J. Zool., 37: 298307.

Dhimal, M., Ahrens, B. and Kuch, U., 2014. Species composition, seasonal occurrence, habitat preference and altitudinal distribution of malaria and other disease vectors in Eastern Nepal. Par. Vec., 7: 1-11. https://doi.org/10.1186/s13071-0140540-4

Edwards, P.M., 2002. Origion 7.0: Scientific graphing and data analysis software. J. Chem. Inf. Comput. Sci., 42: 1270-1271. https://doi.org/10.1021/ ci0255432

Kheir, S.M., Alahmed, A.M., Al-Kuriji, M.A. and AlZubyani, S.F., 2010. Distribution and seasonal activity of mosquitoes in Al-Madinah AlMunwwrah, Saudi Arabia. J. Egypt. Soc. Parasitol., 40: 215-227.

Kioulos, I., Michaelakis, A. and Kioulos, N., 2014. Mosquito (Diptera: Culicidae) fauna in natural breeding sites of Attica Basin, Greece. Hellenic Plant Prot. J., 7: 31-34.
Ilahi, I. and Suleman, M., 2013. Species composition and relative abundance of mosquitoes in Swat, Pakistan. Int. J. Innov. Appl. Stud., 2: 454-463.

Leisnham, P.T., Ladeau, S.L. and Juliano, S.A., 2014. Spatial and temporal habitat segregation of mosquitoes in Urban Florida. PLoS One, 9: 1-10. https://doi.org/10.1371/journal.pone.0091655

Mehmood, A., Naeem, M., Bodlah, I. and Ata-ulMohsin, 2016. Systematics of Anopheles and Armigeres (Culicidae:Diptera) mosquitoes in the Pothwar Region, Punjab, Pakistan. Int. J. Mosq. Res., 3: 5-10.

Naz, R. and Maryam, A., 2014. Population dynamics of mosquitoes in various breeding habitats at University of Peshawar Campus, Khyber Pukhtunkhwa Pakistan. J. Ent. Zool. Stud., 189: 189-195.

Qasim, M., Naeem, M. and Bodlah, I., 2014. Mosquito (Diptera: Culicidae) of Murree Hills, Punjab, Pakistan. Pakistan J. Zool., 46: 523-529.

Rajput, K.B. and Singh, T.K., 1990. Records of Anopheline mosquitoes collected from Manipur with Ecological Notes. Rec. Zool. Sur. Ind., 87: 197-206.

Rajput, K.B. and Kulkarni, S.M., 1990. Records of Culicine mosquitoes from Bastar district (Madhya Pradesh) India (Diptera: Culicidae), Part $\cdot$ I genus Toxorhynchites, Tripteroides, Uranotaenia and Orthopodomyia. Rec. Zool. Sur. Ind., 87: 83-88.

Rattanarithikul, R., Harrison, B.A., Panthusiri, P. and Coleman, R.E., 2005. Illustrated keys to the mosquitoes of Thailand 1. background; geographic distribution; lists of genera, subgenera, and species; and a key to the genera. Southe. Asian J. trop. Med. Publ. Hlth., 36: 1-80.

Reisen, W.K., 1978. A quantitative mosquito survey of 7 villages in Punjab Province, Pakistan, with notes on bionomics, sampling methodology and the effects of insecticides. Southe. Asian J. trop. Med. Publ. Hlth., 9: 587-601.

Tyagi, B.K., Munirathinam, A. and Venkatesh, A., 2015. A catalogue of Indian mosquitoes. Int. J. Mosq. Res., 2: 50-97.

Zahirnia, A.H. and Zendehfili, H., 2014. Mosquito fauna (Diptera: Culicidae) of Hamedan County, Western Iran. J. Arthropod-Borne Dis., 8: 212-218. 